\title{
Usability of Government Websites
}

\author{
Mahmood Ashraf ${ }^{1}$, Faiza Shabbir Cheema ${ }^{1}$, Tanzila Saba ${ }^{2}$, Abdul Mateen $^{1}$ \\ ${ }^{1}$ Department of Computer Science \\ Federal Urdu University of Arts, Science and Technology, Islamabad, Pakistan \\ ${ }^{2}$ College of Computer and Information sciences \\ Prince Sultan University Riyadh 11586 Saudi Arabia
}

\begin{abstract}
Usability of Government websites plays pivotal role in order to provide benefits and services to the citizens. This study presents a usability evaluation for investigating the Nielsen's usability attributes in Government websites. Based on the previous studies, a proposed website template is used in this study. This template is compared with a selected Government website. Thirty (30) participants performed three (3) representative tasks for each website. The results show that the user responses for the parameters of efficiency, memorability and pleasantness are improved for the proposed template. This effort is a part of the study that may lead to the principles for improving the usability of Government websites of Pakistan.
\end{abstract}

Keywords-Usability; statutory bodies websites; government websites

\section{INTRODUCTION}

The Web is currently the main source of providing computer services to reach a larger number of users having different characteristics [1]. After the commercialization has been started on the Internet, the interactive media segment of the Internet, organizations and people hustled to put Web pages and substance on quality of experience that people have is a concern, and one challenge is to ensure the usability of the site [2].

In order to provide government services to the public, Government websites are important windows [3] to its citizens. While visiting a website, usability and user experience are the major challenges [2]. To overcome these challenges, emphasis on usability and user experience is paramount. One way of achieving this is by measuring the easiness of the website's interface [4].

Usability is the quality attribute that measures the easiness of an interface [4]. Battleson et al. (2001) asserted that usability testing is the best approach to asses a website's usability [5]. The meaning of usability, overall, proposes that there are four common factors that influence usability of the interactive system clients, assignments, innovation and setting. The features studied by Bruno et al. (2005), were grouped into above four factors [6].

Usability evaluation concentrates on how well clients can learn and utilize an item to attain their objectives. It also states to how clients are content with that method. To collect this data, specialists use a variety of procedures that collect response from customers about a present site or ideas related to a new site [7]. The articulation, "test early and frequently", is especially fitting with regards to usability testing [7]. There are many methods for the evaluation of usability of the websites like scenario, paper prototype, email, think aloud procedure, co discovery learning, eye tracking and user testing.

This paper reports a user study that was conducted to investigate whether the designed template fulfills the Nielsen's usability attributes. For this purpose a few tasks were set which were performed by thirty users and pre-test was filled before performing these tasks and post-test questionnaires were filled by the users after performing these tasks. Quantitative data was collected through the collection of results on the basis of filled questionnaires and qualitative data was also collected by observing the users.

\section{LITERATURE REVIEW}

The meaning of usability, overall, proposes that there are four mutual factors that influence the usability of the interactive system clients, responsibilities, tools and setting. The features investigated by [6], were come together into these four factors. Many researchers performed usability studies for websites, for mobile web browsing, for older adults. A usability study was performed in which users' mobile browsing experience was evaluated in comparison to desktop Web browsing [8]. Two usability studies were conducted to study whether there were variances in how older adults work together with the Web and whether changes in content size would influence execution [9].

Another research principally focused on Web usability and older adults and set up that even when Web experience is organized, older adults still revealed less Web capability than younger adults. They bolstered the theory that Web aptitude is fundamentally impacted by how clients took in the Web - or their total time spent in community oriented learning situations (gaining from and with others) - instead of exactly to what extent or how regularly they have utilized it [10].

As individuals give careful consideration to the possibility of open administration, government sites end up noticeably vital window to the resident, which can help the legislature to give open administration [3]. In many countries, many researchers performed usability evaluation of many government website. For example: Theory of usability engineer and information architecture was applied on the Canadian Government website [11]. Eleven websites in Zhejiang Province which were of government were taken as samples. Based on the prior research Quasi-experimental study was applied to tell usability issues in these websites and then comprehensive them to a boarder extent [3]. A user study was performed by Yuan and Zhongling having 24 students as participants. Every one of them was understudies with at any 
rate essential site surfing knowledge. Be that as it may, with a specific end goal to make the outcome more powerful and precise, those were chosen who have never utilized government gateways in Zhejiang Province some time recently [3].

In order to understand how to make data vibrant and stressfree to be comprehensible theories have been discussed with respect to following aspects content concise not complicated, structure clear not disorder, data arrangement according to client's judgment not creators' logic, award importance to client familiarity and sensitivity [11]. In order to understand how to provide facts more meaningfully, special attention should be given on the followings. Masterful nature of data conveyance, landing page plan, great structure of peruse and route, without influencing download speed, utilize illustrations, outlines, multi-media and different methods for articulation, well-disposed data interface [11]. As per this examination, utilizing the above hypotheses, the data design of Canada government site has a few components as the accompanying: Rational utilization of shading to express data and give route, help clients comprehend and judge the data substance whenever, diversity of data request and meet the full needs of clients, all-round and multi-dimensional show of data, content fitting [11].

Electronic Government sites of the focal administration of Indonesia was assessed to investigate the ideas and models for gigantic substance sites for creating nations by exploring the qualities and how it spurs the clients in perusing the destinations to look for data and utilize others administrations [12]. Study demonstrated that the clients of Indonesian eGovernment are originated from various social foundation and diverse era hole. They have distinctive recognition and fulfillment to the substance of the e-Government sites. To enhance the ease of use, availability and the adequacy of etaxpayer supported organizations for residents, it is important to accumulate the feeling of the e-Government sites clients by polls frequently to offer a suitable plan and give helpful data [12].

Usability of five websites (Singapore, Korea, Japan, Hong Kong and Malaysia) of Asian countries is performed by Jati and Dominic [13]. Thirty governmental Websites were examined after launching e-government program in Jordan to evaluate ease of access, ease of use, clearness, and approachability to civilians' demand [14]. In view of the assessment comes about and through a manual testing, it was discovered that most of the Websites don't utilize a similar outline, where there ought to be steady and ought to be utilizing similar guidelines and elements [14].

\section{METHOD}

\section{A. Design}

To perform this user study one website of Statutory Body Website has been chosen to compare it with the designed template.

a). Designed Template of SBW (shown in Fig. 1).

b). Frequency Allocation Board

$(\mathrm{FAB})$
To evaluate the usability attributes for these two websites, user study-III Performa was prepared having introduction form, consent form, three representative tasks were designed which were performed by each user for each website. These tasks were performed by each user for each website in different order.

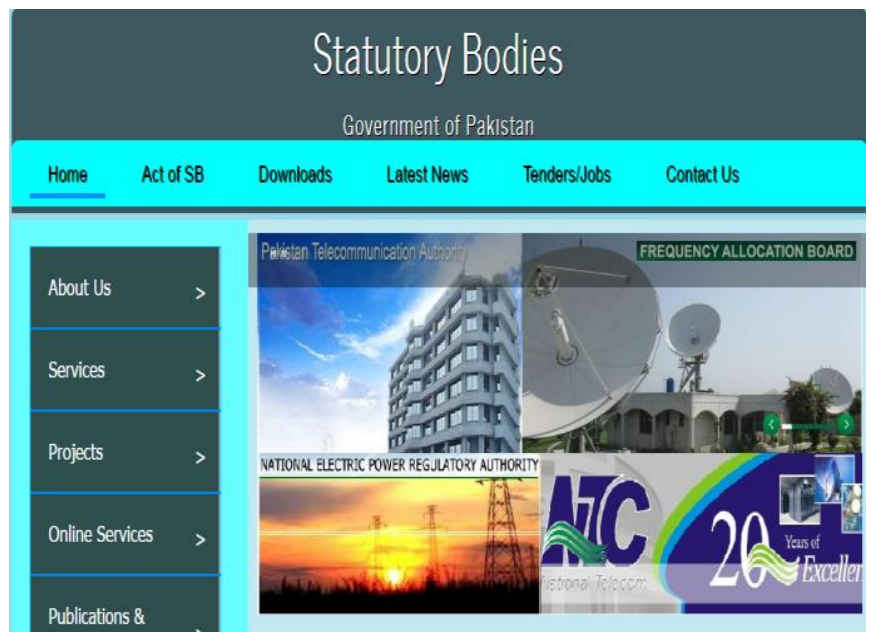

Fig. 1. Designed template of SBW.

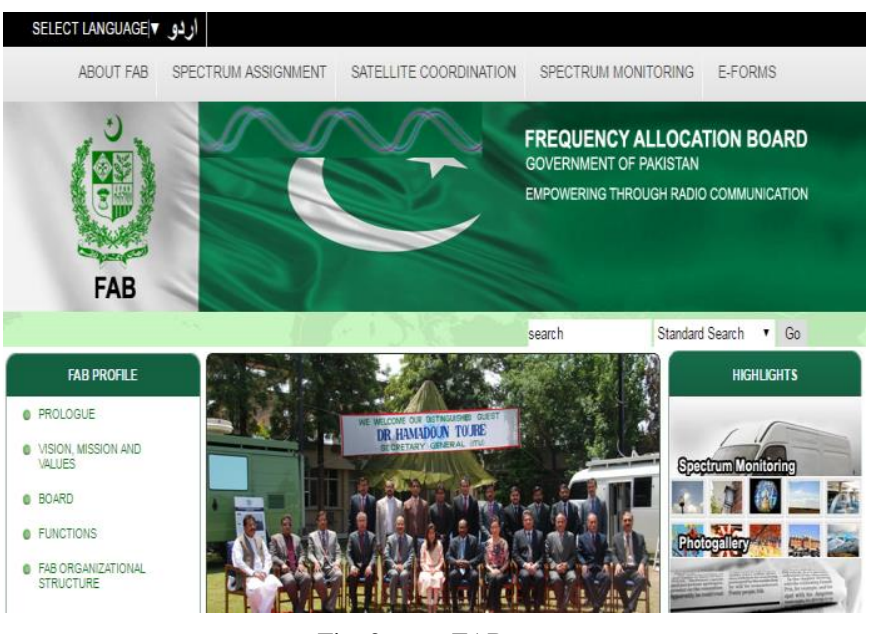

Fig. 2. FAB.

Can you find the following?

a). Phone numbers to contact this organization.

$b$ ). The act of this organization. (This organization is established through the act of Parliament and Act is available on the website.)

c). The vision statement of the organization.

To check the usability of the SBWs, a pre-test questionnaire was prepared to get the general information about the participants.

Post-test questionnaire was prepared to check the usability attributes for these websites. This questionnaire includes the three components of Nielson's attributes of usability which were asked for each website from the users. Each question has two more sub questions so that the in depth information can be taken regarding usability components. (http://www.fab.gov.pk) (shown in Fig. 2). 


\section{B. Participants}

30 participants have performed the tasks for the evaluation of attribute of usability for two websites in different order. Each user performed the tasks for each website. Out of 30 participants $40 \%$ were males and remaining were females.

\section{Experimental Design}

Test was conducted on different dates. At a time only one user was taken to test the usability. Websites were randomly evaluated for usability in different order. Users of different age group and different educational background were taken so that the results cannot be biased. Branded core i3 desktops having Windows 7 were provided to all users with an internet facility to perform this user study.

\section{Procedure}

The participants began the study by first completing the consent form. The previously mentioned four tasks were performed by each user for each website in different order, which is as follow:

\section{COMPILATION OF RESUlTS}

After the performance of the user study, the data were collected and results were carefully analyzed.

\section{A. Pre-Test data Analysis}

According to these results, out of 30, 6 users have qualification MS and 5 have bachelor degree, 17 have master's degree. There was no $\mathrm{PhD}$ user and only 2 had intermediate qualification. All the information of pretest results have been summarized in Table 1.

\section{B. Post-Test Data Analysis (Frequency Allocation Board $(F A B))$}

30 users performed the requested tasks. Two users strongly agreed that it is quick to perform these tasks. 8 users agreed upon that it is quick to perform these tasks. 18 users disagreed and 2 users strongly disagreed that it is quick to perform these tasks. Out of 30, 1 user strongly agreed that home page tasks are quick to perform. 10 users agreed upon while 1 user remained neutral, 17 users disagreed and 1 strongly disagreed. Out of 30, 1 user strongly agreed that other page tasks are quick to perform. 5 users agreed upon while 10 users remained neutral, 13 users disagreed and 1 user strongly disagreed for the quickness of other page tasks as shown in Fig. 3.

One user strongly agreed that it is easy to remember. 8 users were agreed upon that it is easy to remember. 3 users remained neutral while 18 users disagreed and no one strongly disagreed that it is easy to remember these tasks. Out of 30, users strongly agreed that home page tasks are easy to remember. 10 users agreed upon while 5 users remained neutral, 13 users disagreed. Out of 30, 2 users strongly agreed that other page tasks are easy to remember. 2 users strongly agreed that other page tasks are easy to remember, while 15 users remained neutral, 10 users disagreed and 1 user strongly disagreed for the easy to remember of other page tasks.

TABLE I. PRE-TEST DATA ANALYSIS RESUlTS

\begin{tabular}{|c|c|c|}
\hline \multirow{6}{*}{ Qualification } & Matric & 0 \\
\hline & Intermediate & 2 \\
\hline & Bachelors & 5 \\
\hline & Masters & 17 \\
\hline & MS & 6 \\
\hline & $\mathrm{PhD}$ & 0 \\
\hline \multirow{5}{*}{ Age } & Below 20 & 0 \\
\hline & 20-30 years & 8 \\
\hline & $30-40$ years & 18 \\
\hline & $40-50$ years & 4 \\
\hline & Above 50 & 0 \\
\hline \multirow{2}{*}{ Gender } & Male & 12 \\
\hline & Female & 18 \\
\hline \multirow{4}{*}{ Occupation } & Student & 8 \\
\hline & $\begin{array}{l}\text { Government } \\
\text { Officer }\end{array}$ & 12 \\
\hline & Private Officer & 4 \\
\hline & None of these & 7 \\
\hline \multirow{5}{*}{ Use Internet } & Daily & 18 \\
\hline & Once a week & 9 \\
\hline & Once in a month & 1 \\
\hline & Once in a year & 0 \\
\hline & Sometimes & 2 \\
\hline \multirow{2}{*}{$\begin{array}{l}\text { Used Government } \\
\text { Websites }\end{array}$} & Yes & 21 \\
\hline & No & 9 \\
\hline \multirow{5}{*}{$\begin{array}{l}\text { Purpose to use } \\
\text { Government } \\
\text { Website }\end{array}$} & $\begin{array}{l}\text { To get any } \\
\text { information }\end{array}$ & 14 \\
\hline & $\begin{array}{l}\text { To see job } \\
\text { advertisement }\end{array}$ & 12 \\
\hline & $\begin{array}{l}\text { To avail any } \\
\text { service }\end{array}$ & 9 \\
\hline & $\begin{array}{l}\text { For research } \\
\text { purpose }\end{array}$ & 4 \\
\hline & $\begin{array}{l}\text { For any other } \\
\text { purpose }\end{array}$ & 6 \\
\hline
\end{tabular}




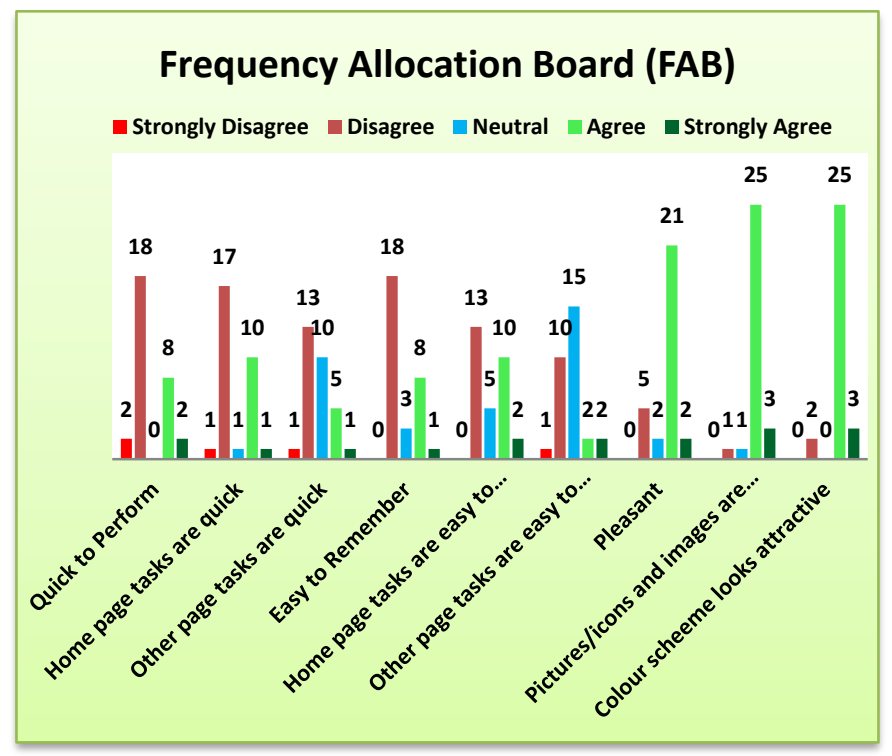

Fig. 3. NAU results of FAB.

Two users strongly agreed that it is feeling pleasant. 21 users agreed upon that it is pleasant. 2 users remained neutral while 5 users disagreed and no one strongly disagreed that it is Feeling pleasant. Out of 30,3 users strongly agreed that pictures, images, icons are beautiful. 25 users agreed upon while 1 user remained neutral, 1 user disagreed, and no one strongly disagreed. Out of 30, 3 users strongly agreed that color scheme looks attractive. 25 users strongly agreed that color scheme looks attractive, while no one remained neutral, 2 users disagreed and no user strongly disagreed.

\section{Post-Test Data Analysis (Designed Template of Statutory Body Website (SBW))}

Thirty users performed the desired tasks mentioned as Annex-A. 27 users strongly agreed that it is quick to perform these tasks. 3 users agreed upon that it is quick to perform these tasks. Out of 30, 28 users strongly agreed that home page tasks are quick to perform and 2 users agreed upon. All the users strongly agreed that other page tasks are quick to perform as shown in Fig. 4.

Twenty eight users strongly agreed upon that it is easy to remember and two users agreed upon that it is easy to remember these tasks. Out of 30,27 users strongly agreed that home page tasks are easy to remember and 3 users agreed upon. Out of 30, 27 users strongly agreed that other page tasks are easy to remember and 3 users agreed that other page tasks are easy to remember.

Twenty eight users strongly agreed that it is feeling pleasant while two users agreed upon that it is pleasant. Out of 30,26 users strongly agreed that pictures, images, icons are beautiful and 4 users agreed upon. Out of 30, 25 users strongly agreed that color scheme looks attractive and 5 users agreed that color scheme looks attractive. It is important to note that no user clicked against neutral, disagree and strongly disagree for all the questions of usability attributes.

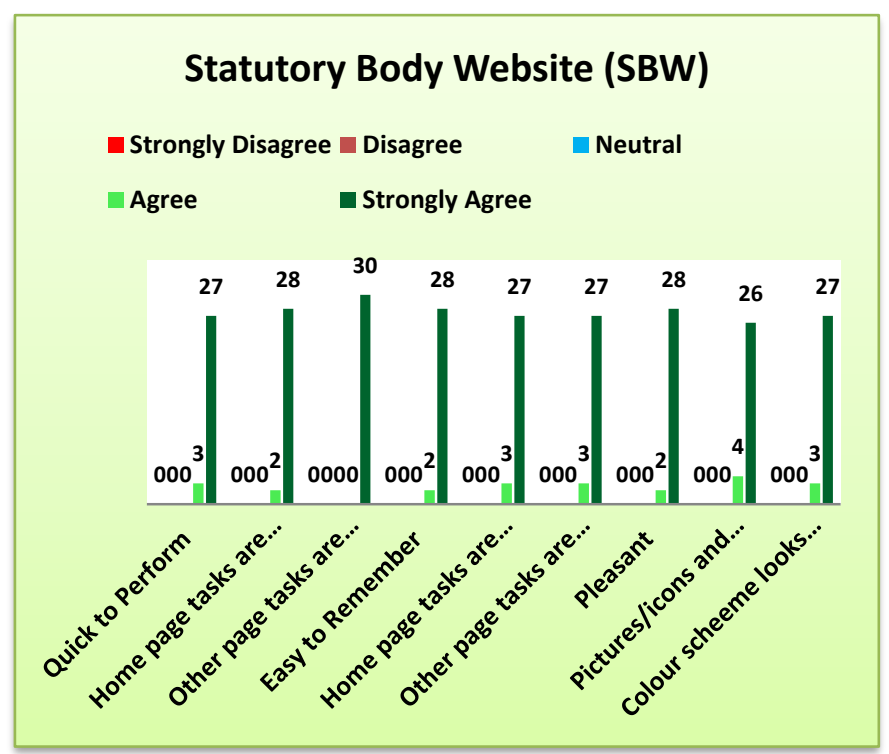

Fig. 4. NAU results of SBW.

V. Results AnAlysis

\section{A. Further Data Analysis of all Websites}

Quantitative results have been collected for this user study, which were evaluated. In user study-I all five components of Neilson's Usability Attributes (NAU) were tested and it was realized that users faced more problems in three components. Therefore, in the second and third user study these three components were tested; Quick to perform, Easy to perform and Pleasantness. For this two more questions were attached against each attribute. Results were compiled for each attribute and shown in Fig. 5.

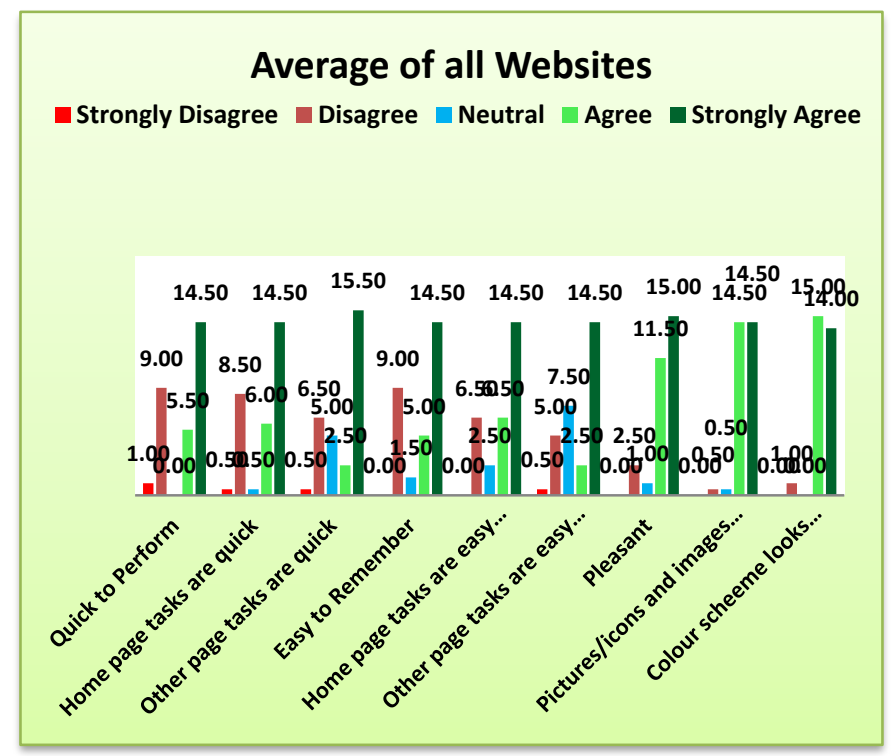

Fig. 5. Average of NAU results of all websites.

\section{B. Quick to Perform}

The average results for quick to perform are 1.00 for Strongly Disagree, 9.00 for disagree, nothing for neutral, 5.5 
for agree and 14.50 for strongly agree. Similarly for quickness of home page tasks the results are 0.50 for Strongly Disagree, 8.50 for disagree, 0.5 for neutral, 6.0 for agree and 14.5 for strongly agree respectively. For other page tasks the results of quick to perform are 0.50 for Strongly Disagree, 6.50 for disagree, 5.0 for neutral, 2.50 agree and 15.5 for strongly agree.

\section{Easy to Remember}

The average results for easy to remember are nothing for Strongly Disagree, 9.0 for disagree, 1.50 for neutral, 5.0 for agree and 14.5 for strongly agree. Similarly for remembrance of home page tasks the results are nothing for Strongly Disagree, 6.5 for disagree, 2.5 neutral, 6.5 for agree and 14.5 for strongly agree respectively. For other page tasks the results of easy to remember are 0.5 for Strongly Disagree, 5.0 for disagree, 7.50 neutral, 2.5 agree and 14.5 for strongly agree.

\section{Feel Pleasant}

The average results for pleasantness are Zero for Strongly Disagree, 2.5 for disagree, 1.0 for neutral, 11.5 for agree and 15.0 for strongly agree. Similarly for pleasantness of icon, images the results are nothing for Strongly Disagree, 2.5 for disagree, 2.5 neutral, 14.5 for agree and 14.5 for strongly agree respectively. For pleasantness of color scheme the results of are nothing for Strongly Disagree, 1.0 for disagree, nothing for neutral, 15.0 agree and 14.0 for strongly agree.

\section{E. Mean and Standard Deviation}

The statistical analysis on the sampled data of both websites is calculated and summarized in the following Table 2.

TABLE II. MEAN AND STANDARD DEVIATION OF ALL WEBSITES

\begin{tabular}{|l|l|l|l|l|l|}
\hline & \multicolumn{3}{|l|}{ FAB } & \multicolumn{2}{l}{ SBW } \\
\hline$\#$ & Mean & SD & Mean & SD \\
\hline Q\#.1 & Quick to Perform & 2.67 & 1.14 & 4.90 & 0.30 \\
\hline Q\#.1 (a) & $\begin{array}{l}\text { Home page tasks are } \\
\text { quick }\end{array}$ & 2.77 & 1.05 & 4.93 & 0.25 \\
\hline Q\#.1. (b) & $\begin{array}{l}\text { Other page tasks are } \\
\text { quick }\end{array}$ & 2.73 & 0.89 & 5.00 & 0.00 \\
\hline Q\#.2 & Easy to Remember & 2.73 & 0.96 & 4.90 & 0.30 \\
\hline Q\#.2. (a) & $\begin{array}{l}\text { Home page tasks are } \\
\text { easy to remember }\end{array}$ & 3.03 & 1.02 & 4.97 & 0.18 \\
\hline Q\#.2. (b) & $\begin{array}{l}\text { Other page tasks are } \\
\text { easy to remember }\end{array}$ & 2.80 & 0.87 & 4.93 & 0.25 \\
\hline Q\#.3 & Pleasant & 3.67 & 0.83 & 4.97 & 0.18 \\
\hline Q\#.3. (a) & $\begin{array}{l}\text { Pictures/icons and } \\
\text { images are beautiful }\end{array}$ & 4.00 & 0.52 & 4.87 & 0.34 \\
\hline Q\#.3. (b) & $\begin{array}{l}\text { Color scheme looks } \\
\text { attractive }\end{array}$ & 3.97 & 0.60 & 4.83 & 0.37 \\
\hline
\end{tabular}

\section{CONCLUSION}

This study analyzes and verifies the influence of three components of usability; efficiency, memorability and pleasantness. A template has been prepared on the basis of the results of user study-I and user study-II. Designed template and the website having poor usability results from previous two studies were selected and tested by the users. Results were compiled and observed that the usability on the designed template of Statutory Bodies Websites has been improved. The results show that the user responses for the parameters of efficiency, memorability and pleasantness are improved for the proposed template. Therefore, we can design rules for the Government of Pakistan on the basis of this work.

\section{REFERENCES}

[1] Dias, A. L., Fortes, R.P.D.M., Masiero, P.C., Watanabe, W.M., \& Ramos, M.E. (2013). "An approach to improve the accessibility and usability of existing web system." Proceedings of the 31st ACM international conference on Design of communication. Greenville, North Carolina, USA, ACM: 39-48.

[2] Davis, P. A. \& Shipman, F. M. (2011). Learning usability assessment models for web sites. Proceedings of the 16th international conference on Intelligent user interfaces. Palo Alto, CA, USA, ACM: 195-204.

[3] Yuan, L., \& Zhongling, L. (2010). Experimental evaluation on government portal website's usability to 11 government websites of Zhejiang province. doi:10.1109/ICISE.2010.5688953

[4] NNGROUP. (2012, January 4, 2012). "Nielson Norman Group." Retrieved 11th May, 2015, from http://www.nngroup.com/articles/usability-101-introduction-tousability/.

[5] Battleson, B., Booth, A., \& Weintrop, J. (2001). Usability testing of an academic library Web site: A case study. Journal of Academic Librarianship, 188-198.

[6] Bruno, V., Tam, A., \& Thom, J. (2005). Characteristics of web applications that affect usability: a review. Proceedings of the 17th Australia conference on Computer-Human Interaction: Citizens Online: Considerations for Today and the Future. Canberra, Australia, Computer-Human Interaction Special Interest Group (CHISIG) of Australia: 1-4.

[7] Usability. (n.d.). In Usability. Retrieved August 24, 2015, from http://www.usability.gov/

[8] Shrestha, S. (2007). Mobile web browsing: usability study. Proceedings of the 4th international conference on mobile technology, applications, and systems and the 1st international symposium on Computer human interaction in mobile technology. Singapore, ACM: 187-194.

[9] Chadwick-Dias, A., McNulty, M. \& Tullis, T. (2003). Web usability and age: how design changes can improve performance. Proceedings of the 2003 conference on Universal usability. Vancouver, British Columbia, Canada, ACM: 30-37.

[10] Chadwick-Dias, A., Tedesco, D., \& Tullis, T. (2004). Older adults and web usability: is web experience the same as web expertise? CHI '04 Extended Abstracts on Human Factors in Computing Systems. Vienna, Austria, ACM: 1391-1394.

[11] Zhou, X. (2009). Usage-Centered Design for Government Websites - A Practical Analysis to Canada Governmant Website. doi:10.1109/ICIC.2009.84

[12] Nariman, D. (2010). E-Government Websites Evaluation Using Correspondence Analysis. doi:10.1109/CISIS.2010.13

[13] Jati, H., \& Dominic, D. D. (2009). Quality Evaluation of E-government Website Using Web Diagnostic Tools: Asian Case. doi:10.1109/ICIME.2009.147

[14] Al-Soud, A. R., \& Nakata, K. (2010). Evaluating e-g overnment websites in Jordan: Accessibility, usability, transparency and responsiveness. doi:10.1109/PIC.2010.5688017 